\title{
Ecology in Technology: The Problem of Developing Technology Readiness Level in Terms of Ecology
}

Murad Muradovich Brutyan*

Central Aerohydrodynamic Institute named after Prof. N. E. Zhukovsky, Russia; btm23@mail.ru

\begin{abstract}
Objectives: To improve the modern approach to assessment of technology readiness level in the case of development of technology for high-tech industries, the products of which significantly affect environmental ecology. A vivid example of this kind of industries is the aviation industry. Methods: Such methods of research as systematic and logical approach, economic analysis and model development are applied. Findings: The main research finding is the development of a new additional readiness level "Ecology", for which questions and required evidence necessary for passing it in the framework of the modified technology readiness level chain were formulated. An innovative parallel civilian aircraft constructional design concept was developed with consideration of the formulated additional ecological technology readiness level. Applications/Improvement: The possibility of practical implementation of the proposed approach is shown by filling the aviation technology validation checklist which includes requirements for aviation environmental protection. The necessity of final validation of aviation technology aimed at reducing the negative impact of aircraft on the environment is illustrated and justified.
\end{abstract}

Keywords: Aviation Technology Validation, Civil Aviation, Eco Design, Ecology, Technology Readiness Levels

\section{Introduction}

Currently, in the context of globalization and transfer of a number of developed countries to an innovative model of economy, it is technology that allows creating innovative products; provide competitive advantages in the

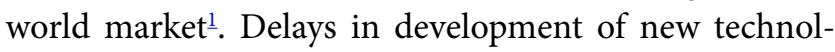
ogy, especially in strategically important areas such as aircraft industry, can significantly reduce overall national economy technological level and consequently, national security level. It is widely known that the science is primary and the economy is secondary. New advanced technology can appear only due to science, as a result of scientific research and scientific discoveries. The process of transforming scientific knowledge and information into competitive innovations is, in its essence, an innovation process ${ }^{2}$. K. Marx emphasized that science is the most fundamental form of wealth. It is both a product and a producer of wealth ${ }^{3}$. In this regard, the most impor- tant element of the applied research and development management system is assessment of level of availability of an advanced technology before its transfer to the next readiness level (development stage). The process of development of new technology inevitably faces these three main problems: funding level, completion schedule and performance schedule. It is clear that timely funding in full reduces uncertainty and extent of risk for all these three problems.

For the purpose of this paper, technology is application of knowledge in practice in order to create opportunity to do something completely new or in an entirely new way. This is how the concept of technology differs from scientific research, which is intended for discovery of new knowledge that contributes to the creation of a new advanced technology and from technical development that uses a technology obtained on the basis of such knowledge to solve specific practical tasks. To assess technology readiness level, many specialists in the field of 
innovative, technological and design management widely recognize the methodology for assessing Technology Readiness Level (TRL) ${ }^{4}$.

\section{Materials and Methods}

In course of the research, the following methods were applied: Systematic and logical approach, economic analysis and model development. In addition, much attention was paid to the study of the expert and test methodology of TRL and to the problem of its adaptation for the needs of innovative projects significantly affecting matters of ecology.

TRL approach is usually formulated based on standards developed by NASA (USA) in the 1980s for assessing the maturity of aviation and space technologies. The need to develop and implement such a system was stimulated by the General Accounting Office, which identified over expenditures and delays in the schedule of delivery of the ready systems in the framework of implementation of large-scale weapons procurement programs that were ordered by the US Department of Defense. In fact, the reason for this was an incorrect assessment of the technology and production readiness level. Currently, TRL system can be used in aerospace and other high-tech companies to determine current status of a technology, better understand the real situation and assess risks associated with further development, efforts necessary to achieve the required maturity of a new technology and to reduce risks associated with integration of technology into the system. This methodology for assessing the technology maturity has become widespread in many large government departments and organizations of the US, as well as in a number of its advanced high-tech innovative companies. So, for example, in the US, in addition to NASA, TRL system is implemented in the Department of Defense, the Federal Aviation Administration, the Department of Energy, such companies as Boeing, Lockheed Martin, Northrop Grumman, General Electric, Pratt and Whitney, Ford, Kodak, etc. TRL system is also abundantly used in Europe, it is integrated in such departments and organizations as the UK Ministry of Defence, the European Space Agency, Airbus, BAE Systems, Rolls-Royce, BMW, Ferrari, FIAT, Nokia, French energy companies, Nexter (armored vehicle production) $)^{5}$. TRL system is given much attention by some departments and companies of Australia, Japan, Canada, the Netherlands,
Germany, Finland, Sweden and Singapore. China's interest in TRL approach also increases. Chinese scientists have conducted a series of studies and published several scientific papers on TRL ${ }^{6}$. Russia is also interested in the integration of TRL methodology, for the needs of aviation and shipbuilding industries ${ }^{\mathrm{z}}$. Thus, in the Krylov State Research Center, it was suggested to apply TRL approach for development of the advanced technology (R\&D area); a stage-gate system is intended for the support of integrated design, development and manufacture of product innovations.

\subsection{Enhancement of Technology Readiness Level Methodology taking Ecological Parameters into Account}

The TRL methodology provides for consistent support for a complete innovation cycle divided into stages of knowledge generation, transformation of knowledge into experimental development and commercialization of technology. Extension of terms for development of new technology almost always results in a decrease of technical and economic indicators of production and in a decrease of the product competitiveness. For example, the delay in putting KAMAZ into operation for a year and a half eventually led to the loss of several billion dollars by the Soviet Union. This example from the practice of implementation of large-scale projects clearly emphasizes the importance of using an effective approach for forecasting the development of technology, managing the process of their creation, adequate assessment of their current maturity level. In addition to using TRL methodology in order to reduce the risks associated with implementing scientific and technical innovation projects, methods for assessing the level of maturity of production, logistics, marketing and software may also be helpful.

TRL scale serves as a good logical tool for assessing the technology development level, which links well the goals and objectives of the project in the medium to long term. In the context of ICAO's definition of standards for the International Civil Aviation Organization, long-term goals and objectives range from TRL 2 to TRL 5, while medium-term ones - from TRL 6 to TRL 7. Technology reaching TRL 8 is recognized technically feasible. This includes those technology the suitability of which has already been confirmed and is either already certified, or will be put into operation in the nearest future upon cer- 
tification. TRL system is an important tool for assessing readiness level of aviation technology with less negative impact on ecology.

Aviation technology in terms of aviation environmental protection can be conditionally divided into three categories:

- Technology incorporated into equipment which is already in operation;

- Technology that can be introduced in future production versions of certain aircraft;

- Technology and concepts, available only in fundamentally new aircraft designs.

It should be noted that the first group of technology can provide the greatest and immediate effect regarding environmental protection, as they are available for introduction either immediately or at the earliest date. In fact, they are only a modification of current operating version of certain aircraft. The second group includes technology which is either too complex or too expensive. However, such technology has great potential when applied with the newly created modified production versions of an aircraft. This technology works both independently and in combination with existing technology, which, taken together, promises an even greater positive integral effect. Finally, the last group of technology ranged as early TRL can be used only in the case of development of totally new aircraft systems based on new aircraft design concepts. Aviation technology attributed to the latter group usually require significant expenditures for $\mathrm{R} \& \mathrm{D}$, a higher degree of risk and about two decades on the average required to complete development. This group of technology is often the most promising. At the same time, it is difficult to assess it due to the high degree of uncertainty associated with low current maturity level.

A comprehensive assessment of aviation technology, taking environmental requirements into account, should consider advantages of various types of fuel efficiency technology, reduction of harmful emissions, reduction of noise pollution, reduction of the impact on climate change, taking into account performance rates of particular aircraft, the required investments and operational expenditures. Socially significant advanced technology in the aircraft industry and some other high-tech sectors of the economy almost always affects, and will affect the global ecosystem. This is primarily due to the negative impact of noise and emissions of harmful substances into the atmosphere on human health. Therefore, under present conditions of toughening of environmental standards, the stage of assessment of environmental and economic efficiency of an innovative project being implemented becomes one of the most important. Over the past 65 years, the role of environmental factors in civil aviation has significantly increased, second only to the paramount issues of flight safety. It should be mentioned that today's trends are such that ecology issues are often considered as important as primary security issues.

Committee on Aviation Environmental Protection (ICAO) sets a strategic goal to minimize the negative impact of global civil aviation on the environment. This requires the implementation of three related measures:

- Limiting or reducing the number of people exposed to significant aircraft noise;

- Limiting or reducing the impact of aircraft engine emissions on air quality in population centers;

- Limiting or reducing the impact of greenhouse gas emissions on the global climate.

\section{Results and Discussion}

Considering the importance given to environmental protection by international regulatory agencies and individual governments regulating civil aviation, it can be concluded that at the present stage of society development, in course of development of socially important technology, it is necessary for them not only to have economic and technical efficiency, but often be environmentally safe.

In this connection, the author makes an attempt to improve TRL system by introducing an additional "ecological" level of technology readiness into the classic TRL approach. The modified TRL chain in this case provides for $9+1$ readiness levels (Figure 1). Main purpose of readiness levels from 1 to 9 is briefly formulated in captions in Figure 1. Criterion of compliance with the proposed new additional "ecological" technology readiness level is formulated as follows:

Level "ecology": Ecological and economic expertise of the main critical functions and most important parameters of a new technology have been validated and the most important environmental aspects that affect a proposed technological innovation have been identified.

A necessary task while using the modified TRL scale is the formulation of basic requirements and the evidence necessary for validation of a technology prior to moving 
to the critical stage of design and stage of direct integration of technology into particular system. The formulated additional block is of great practical importance, since if there is a discrepancy between environmental and other standards, the finalization of design at subsequent stages of TRL (TRL 5 and further), and moreover at the stage of serial production and operation, will affect significantly the entire project. For example, when talking about innovative projects for the development of aviation equipment, adjustment of design parameters here is subject to "rule 1-10-102". This means that if the cost of adjustment at the design stage is taken as one, then the cost of adjustment at the production stage will be ten times more expensive, and at the operational stage hundred times more expensive $^{8}$. Rule " $1-10-10^{2 "}$ is relevant for almost any, from construction to advertising projects. The general logic of this principle is simple: the more qualitatively the work will be performed in the early stages, the less the costs will be at the following stages.

Main considerations and evidence required for them at the auxiliary (environmental) level can be presented as follows:

Question 1: Was a new concept or a new technology sufficiently clearly described so that it would be possible to confidently predict the extent of its influence on the ecosystem? Based on this description, is it possible to draw a conclusion about feasibility of its implementation, taking into account possible environmental constraints?

Question 2: Were the main environmental requirements and limitations established as precisely as possible in terms of the intended use of the technology? Were these requirements chosen with consideration of intended operational environments and of the expected testing environments for the technology being developed, where it will be possible to ensure that the established standards would be met? Can a list of expected fields of application and operating environments for this technology be compiled?

Question 3: Were the main environmental aspects (theoretically or experimentally) that will be affected by the new technology (described in Question 1) identified (theoretically or experimentally) so that it can be concluded that the new technology meets the basic requirements (described in Question 2)? Is it possible to conclude that the developed technology will be used in accordance with the list of intended applications? What indicators were used to assess economic feasibility of further technology development? In case an experiment was conducted - was it conducted properly and with reasonable accuracy?
Question 4: Is there a feasible way leading to further advancement of technology taking the influence of environmental factors and economic forecasting into account? Is it possible to conduct supporting experiments to confirm feasibility of environmental requirements and constraints? What additional resources and opportunities are needed to follow the planned course? Can technical risk and efforts to overcome it be assessed?

Required evidence (answers to questions asked):

Evidence 1: Detailed description of main provisions (critical functions) of a concept or a basic technology that is likely to affect environmental aspects. Collection of all currently available documentation related to similar phenomena that similarly affect the ecosystem, a thorough examination of current legislation governing environmental management and environmental measures. Conduction of environmental and economic expertise and assessment of the expected profitability of the technology is to be introduced.

Evidence 2: Clear and detailed description of basic requirements for the technology being promoted in order to find out whether this innovation can in general comply with the desired requirements and be technically implemented taking environmental constraints into account, while ensuring that its implementation is commercial profitable. Description of possible fields of applications for this technology taking into account the influence of environmental factors. If necessary, identification of specific (acceptable) operating environments.

Evidence 3: Providing and analyzing all the documentation detailing the theoretical and/or experimental studies that lead to the conclusion that the technology fits into the existing "ecological frameworks" and does not require any technical assistance for finalization of the concept. Providing materials persuading that, from the perspective of possible fields of application and intended operational environments, environmental requirements have been established correctly. Assessment of economic feasibility of further technology development.

Evidence 4: Strong evidence that the influence of environmental factors on the further technology development has been comprehensively studied and, if necessary, that the relevant changes to the concept have been made and that this innovation can be technically and economically justified for transfer to the next - fifth level of readiness TRL 5.

Ignoring of the TRL stage "Ecology" can in some cases cross out all the benefits of an advanced technology, 
even if it is technically implementable in the form of final product. This way, for example, when constructing specialized vessels - lighter carrier ships of "Savannah" type, it was assumed that they would be quite economical and highly profitable, since there had already been experience in using nuclear power plants by the navy. However, the powerful movement of the "green" against the use of such plants in the civilian fleet brought all the advantages of such vessels to nothing, and cut all commercial use to the only one sailing by "Savannah". This example illustrates the importance of consideration of environmental factors in the early stages of design.

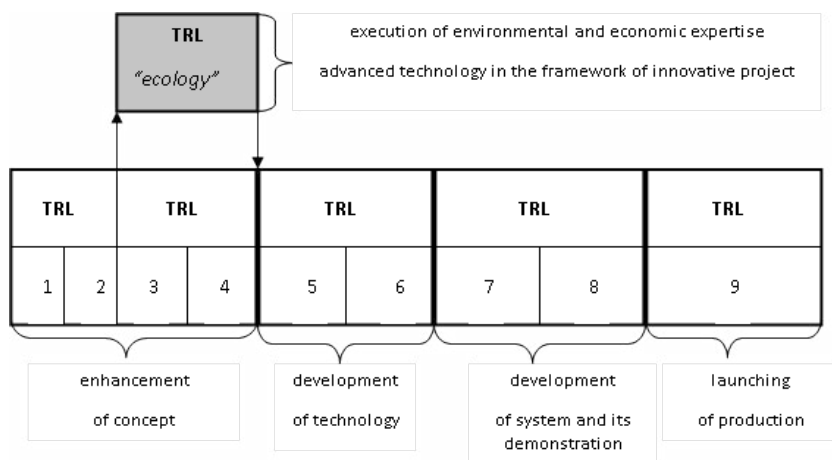

Figure 1. Chain of technological development with consideration of environmental factors.

\subsection{Opportunities for Implementation of the Advanced TRL Methodology Concept}

As you know, the classic TRL approach was implemented as a special calculator executed in Microsoft Excel environment to measure the technology readiness level and graphically display TRL indicator on a consumer's screen. The ability to assess current level of technology maturity undoubtedly simplifies the project management process, reduces the degree of uncertainty regarding technology development success by reducing specific risks. While acknowledging that TRL calculator was programmed according to the "question to consumer - answer from consumer" principle, the assessment of TRL "Ecology" pass should be based on the same logic, but with direct participation of independent profile experts who must assess either correctness or incorrectness, as well as the degree of completeness of the assessor's answers to the questions.

Table 1 provides an example of implementation of the approach to assessment of TRL "Ecology". The first column of the table contains special formulated questions to the developer, the second column includes developer's answers given, and in the third column specially invited experts determine whether the developer's answers to the specially asked questions were correct. An example of filling in of such a table is presented below.

Assessment of a technology readiness at the proposed supporting (ecological) level is intended to establish or predict the impact of the technology being developed on the ecosystem, followed by economic analysis and modeling of the technology use, with consideration of environmental constraints, in order to establish the profitability of an innovation project as a whole. Economic assessment is carried out at this stage not with the aim of determining the standard commercial scheme "revenue - costs = profit" and not even with the aim of forecasting future cash flows taking discount rates into account, but in order to determine the influence of ecological factors on technology feasibility and launch of production line. The main issue at this stage is: Will the considered technology fit into the standards of modern environmental requirements or not? If not, is it possible to revise and improve the technological concept in such a way that the requirements can be met? At this stage of technological readiness for assessment, scientists, engineers and technologists who are able to predict the impact of technology on the environment, as well as a group of independent experts (economists and ecologists) who understand well environmental and economic modeling should be involved. Technically and environmentally competent representatives from potential future consumers and operators are also required.

When passing TRL "Ecology", it is necessary to finally formulate a technological concept, justify the proposed design, chosen materials, etc. in order to confidently engage in further development, without fear of possible environmental risks. At the same it shall be noted that during additional environmental examination, which begins after TRL 3, technology development still continues. The presented additional block represents a kind of "superstructure" above technological chain within TRL 3 - TRL 4 interval. Currently, successful pass of TRL "Ecology" is an important stage in the development of advanced technology and assessment of readiness of their integration into the aviation system.

\subsection{Eco Design using Example of Creation of Civil Aircraft}

When passenger aircraft built according to technologically completed projects go on sale, buyers have a dilemma. Most aircraft comply with modern technical 
Table 1. Aircraft validation checklist with consideration of ecological requirements on aviation environmental protection

\begin{tabular}{|c|c|c|c|}
\hline No. & Question to developer & Answer of developer & Assessment by expert \\
\hline 1 & $\begin{array}{l}\text { Do theoretical and/or experimental } \\
\text { modeling methods adequately reflect } \\
\text { and fulfill the necessary conditions for } \\
\text { environmental verification? }\end{array}$ & $\begin{array}{l}\text { 1. Modeling does not } \\
\text { adequately reflect the basic } \\
\text { conditions. } \\
2 . \text { The necessary conditions } \\
\text { (factors) of surrounding } \\
\text { environment were, where } \\
\text { possible, taken into account. } \\
\text { 3. Modeling accurately reflects } \\
\text { all the basic conditions. }\end{array}$ & $\begin{array}{l}\text { - Developer gave wrong } \\
\text { answer to the question } \\
\text { (0 points) } \\
\text { - Developer gave } \\
\text { incomplete answer } \\
\text { to the question (1-2 } \\
\text { points) } \\
\text { Developer gave cor- } \\
\text { rect answer to the } \\
\text { question (3 points) }\end{array}$ \\
\hline 2 & $\begin{array}{l}\text { What are the limitations of environmental } \\
\text { validation for the model used? }\end{array}$ & $\begin{array}{l}\text { 1. There are no constraints. } \\
\text { 2. There are the following } \\
\text { constraints: (listed...) }\end{array}$ & $\begin{array}{l}\text { - } \text { See above } \\
\text { - See above } \\
\text { - See above }\end{array}$ \\
\hline 3 & $\begin{array}{l}\text { For those parameters that are not } \\
\text { modeled, can a reasonable quantitative } \\
\text { assessment be obtained? If it is possible, } \\
\text { then how? }\end{array}$ & $\begin{array}{l}\text { 1. Not to be assessed. } \\
\text { 1. To be assessed as follows } \\
\text { (described...) }\end{array}$ & $\begin{array}{l}\text { - } \text { See above } \\
\text { - } \text { See above } \\
\text { - } \quad \text { See above }\end{array}$ \\
\hline 4 & $\begin{array}{l}\text { Is it possible to confidently and } \\
\text { reasonably discuss economic feasibility } \\
\text { (creation of added value) of further } \\
\text { development of this technology in view of } \\
\text { its impact on the environment? }\end{array}$ & $\begin{array}{l}\text { 1. One can confidently assert } \\
\text { about the feasibility of further } \\
\text { development. } \\
\text { 2. Further development is not } \\
\text { economically justified. }\end{array}$ & $\begin{aligned} & \text { See above } \\
& \text { - } \text { See above } \\
& \text { - } \text { See above } \\
& \text { Total } \boldsymbol{\Sigma}=\end{aligned}$ \\
\hline
\end{tabular}

requirements, so to choose the best offer; buyers have to be guided by different criteria, rather than just technical characteristics of the aircraft. Customers (potential buyers) will have to use a certain methodology to assess the effectiveness of the entire innovative design of a particular aircraft, rather than paying attention to minor differences in technical characteristics, design or interior furnishing. It is clear that the cost of operation of a product will have a huge impact on making a reasoned decision. Assessment of operational efficiency of the aircraft is a complex interdisciplinary problem, in which technology, finance and politics are closely interlocked. In connection with the recent tendency in civil aircraft industry to tighten environmental standards in terms of number of harmful emissions and noise exposure, potential operators (airline companies) are beginning to pay increasing attention to an "ecologically sound" aircraft. Economically, this is explained by the fact that airfield charges and fines for exceeding environmental standards are borne entirely by the airline company, which accordingly reduces its potential profit and, even in some cases, can make business unprofitable. Obviously, in this situation, those products that promise the greatest economic benefit with consideration of environmental tax will be in greater demand in the market. Therefore, when creating an innovative project for a passenger aircraft, developers (aircraft construction companies), as well as future operators, should be interested in considering the environmental factor as one of the most important parameters of the future economic efficiency of the project as a whole.

When choosing optimal aircraft parameters, environmental factors are not always taken into account in advance. In some cases, their impact is assessed after the adoption of a managerial technical solution. Obviously, such a "consistent" design methodology (Figure 2) is not optimal today and in the near future, consideration of 
harmful emissions and noise should become a necessary component at an early stage of a new "parallel" design methodology (Figure 3) and the choice of optimal aircraft parameters (along with aerodynamics, integrity, power supply and control system).

Obviously, such a design methodology contains great risks and for a number of reasons (environmental tax, airfield charges, etc.) is not optimal from the point of view of economic efficiency. In this connection, there emerges an actual task of development of an innovative approach to design - eco design. According to the definition provided by the European Commission, eco design is integration of environmental parameters into product design in order to improve its ecological efficiency throughout its life cycle ${ }^{9}$.

In the context of eco design in the near future, the calculation of harmful emissions and noise should become an essential component of the project development at an early stage of a new "parallel" methodology of eco design and selection of optimal parameters (see Figure 3).

Ecology issues should be put on a par with traditional main problems of aircraft aerodynamics, integrity, power supply and control system, which will allow to take environmental risks timely into account and thereby, increase the economic efficiency of the entire project ${ }^{10}$. This measure is well-timed, because correction of design parameters at later stages, as already mentioned above, will cost substantially more expensive for the developer. In this regard, the innovative design concept reflects the previously described advanced approach to TRL, which involves consideration of environmental factors when developing advanced technology already at the stage of enhancing of the product concept. Therefore, we can say that successful passage of TRL "Ecology" means transfer to the concept of eco design. Of course, the eco-innovative approach to design accumulates more resources (it is more expensive) in the early stages of creating a system product, but later it helps to avoid high costs associated with attempt to reduce adverse environmental impact, which is especially important for products with a long service life.

Organization, under the influence of the increased importance of environmental issues and the need to meet the requirements of sustainable development, also undergoes changes relating primarily to management techniques and approaches to management that it applies. Increasing importance of environmental factors to management decisions has a strong influence on the design organization and can even eventually lead to the trans- formation of the entire organizational and management mechanism ${ }^{11}$.

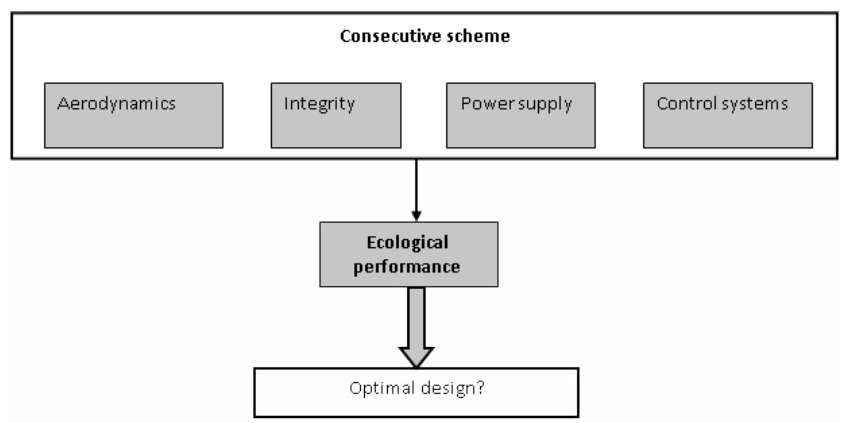

Figure 2. Traditional "consecutive" design scheme for civil aircraft.

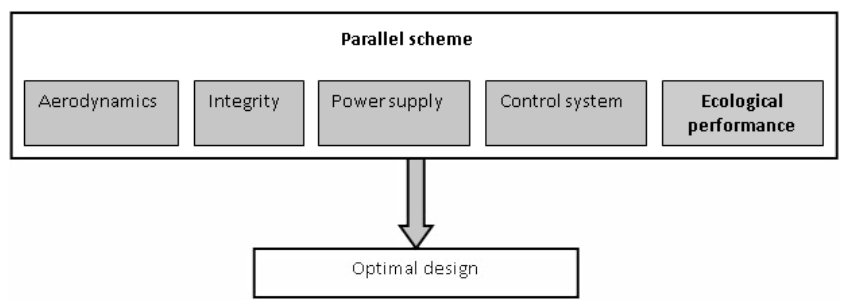

Figure 3. Innovative "parallel" design scheme for civil aircraft.

\subsection{Final Validation of Aviation Technology Developed within the Framework of the Eco-Innovative Design Concept}

Aviation technology can be defined as a set of design and technological documentation describing the way to obtain unique characteristics of an aircraft, its systems or elements, including methods of manufacturing (production), as well as composition of aviation materials ${ }^{12}$. Technology ecological validation establishes a mechanism for objective verification of functional characteristics of future products in order to increase confidence of potential consumers in accordance with modern environmental requirements and standards.

Formation of requirements for the final validation of aviation technology implies merging of the basic technical requirements that consumers put forward to aviation systems in a way that helps to best achieve mutual goals and obligations between developers (industry) and customers (government and airlines). Prerequisites for the formation of requirements can differ. For example, the Japanese economist T. Kono believes that there are four main sources forming requirements for innovative technology ${ }^{13}$ : 
- Market needs;

- Science and technology possibilities;

- Companies needs and policies;

- Repetition and imitation of competitors.

The concept of validation should be distinguished from the concept of verification. Thus, in accordance with the ISO 9000 standard, validation is confirmation (on the basis of provision of objective evidence) that the requirements for a particular use or application are met $^{\frac{14}{4}}$. Verification precedes validation and is almost always carried out to determine whether the product meets the specified requirements. Validation also gives an answer to the question whether a technology or a product that meets the established requirements can be applied in a particular situation to solve the task.

In view of Russia's recent entry to the World Trade Organization and in connection with the enactment of Federal Law No. 184-FZ “On Technical Regulation”, the importance of having certified and efficiently functioning Quality Management Systems (QMS) at ISO 9000 international standards increases. QMS is a combination of the organizational structure, methodologies, processes and resources needed to confirm (validate) product quality ${ }^{15}$. As to requirements for QMS of aviation, space and defense organizations, they are regulated by a series of standards AS/EN 9100. Schematically, the process of deciding on whether to perform validation is shown in Figure 4.

The presented model describes a "tree" according to which the manufacturer can make a decision about the need to validate a technology or a process or to calculate that it is enough to carry out verification only. This example illustrates the simplest version of validation of a technology or a process. Technology system and the set of processes will require a more complex and integrated approach. Each technology and process must have its own specification describing the desired output data. The manufacturer must calculate whether these output parameters can be checked by subsequent measurement and control. If the answer is positive, then a decision as to whether sufficient checks are sufficient to eliminate the unacceptable risk and to make an economically justified decision, i.e. whether this verification is sufficient, should be made. If so, verification can be successfully carried out and one just needs only to successfully monitor and manage further processes. In this case, we can speak about verification effectiveness.
If the output data cannot be verified, then there are two possible alternatives:

- Checking and validation without verification;

- Redesign and enhancement of technological product with subsequent verification.

The need for the development of engineering methods and approaches to technology validation for various aviation and space systems is of particular relevance. Such techniques are designed to optimize the costs and time associated with creation of high technology and its integration into particular system. Complex verification and validation process, which includes both analytical, numerical simulation, and experimental methods, seems most promising.

When formulating the list of requirements for the validation of innovative aviation technology in terms of reducing environmental impact, in accordance with the methodology for formulation of objectives S.M.A.R.T., it is necessary to adhere to a number of conditions ${ }^{16}$ :

- Requirements must be specified, clearly formulated;

- Requirements must be measurable or assessable, i.e. include an indicator by which the degree of goal achievement can be assessed;

- Requirements must be achievable, which implies availability of the necessary amount of resources for achievement of the goal;

- Requirements must be relevant;

- Requirements must be well-timed, the deadline for implementation be indicated, after which the assessment of the goal achievement shall be carried out.

The list of requirements for validation of innovative aviation technology in terms of reducing their environmental impact, in accordance with the conditions described above, may be as follows:

- Validation should be carried out by specialists highly qualified in the field this innovative technology belongs to, together with a team of environmental specialists;

- Validation should be carried out with the equipment certified, including by ecologists, under controlled conditions; 
- Validation should be carried out in terms approved and agreed with the environmental service.

Final validation of a developed aviation technology within the framework of the system should be carried out at TRL 9 during regular operation of the system in flight conditions. At this level of technology development, it is necessary to demonstrate its operational capability on real developed devices installed on the aircraft. For example, a real engine is installed as one engine on a multi-engine aircraft, and flight tests can then be carried out. At this final stage, a new technology must finally confirm not only its performance, but also environmental efficiency. In case it does, a decision about its use on serial products can be made.

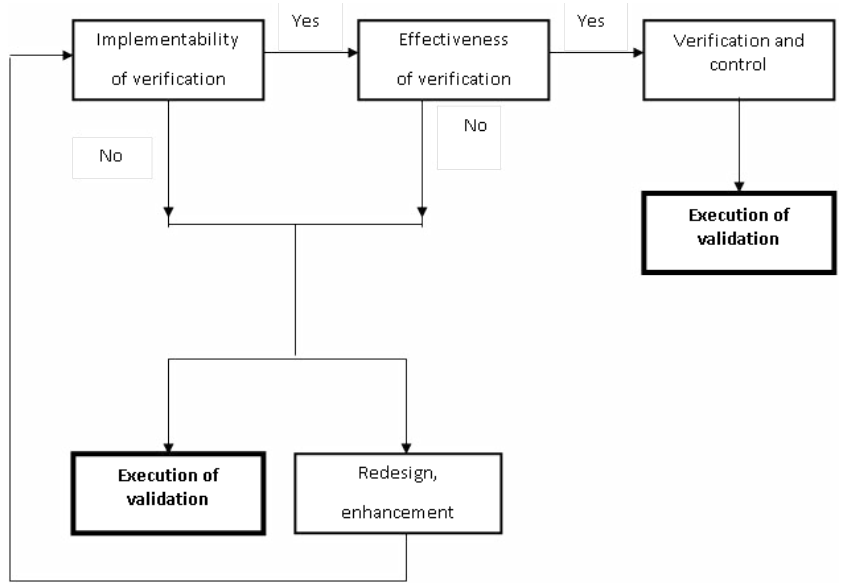

Figure 4. "Tree" of decision-making on technological processes validation.

\section{Conclusion}

The eco-innovation approach to design accumulates a more significant amount of resources (is more costly) at the design stage and at the beginning of the operation stage, in contrast with the traditional approach. However, this approach makes it possible in the future to avoid higher costs associated with an attempt to reduce negative environmental impact during the operation and disposal stages. Therefore, for products with a long life cycle, which undoubtedly include civil aviation aircraft, the eco-innovative approach to design becomes economically more expedient than the traditional consistent approach, which does not take the influence on the environment into account at early stages. The international practice knows cases when technological innovation successfully passed all the stages of development corresponding to nine TRL stages, but in the course of already well-established serial production and operation, a circumstance, or a legislative decision based on environmental factors, limiting or even prohibiting the use of this technology was revealed. This kind of circumstances can make technology unprofitable, even if it is technically feasible. Therefore, passing TRL "Ecology" developed in this paper is an important stage in the successful process of introducing and commercializing promising high technologies used in system products having a significant impact on ecology of the environment.

\section{References}

1. Lerner J, Stern S. Innovation Policy and the Economy. The University of Chicago Press. 2009; 10:1-176.

2. Vinitsyna VV, Gaifutdinova OS, Gorshenina PM. Factors of sustainable development of the regions of Russia: a monograph. Novosibirsk. 2009. p. 326.

3. Economic flows in the development of integration processes. 2017. https://www.researchgate.net/ publication/316035413_Economic_flows_in_the_development_of_integration_processes

4. Mankins JC. Technology Readiness Levels. A white paper. 1995. p. 1-4.

5. Slivitskiy A. Regions of Eurasia: Strategies and mechanisms for modernization, innovation and technological development and cooperation. Proceedings of the 1st International Scientific-Practical Conference; Moscow, Russia. 2013. p. 270-8.

6. Wang Y, Liu J. Evaluation methods for the autonomy of unmanned systems. Chinese Science Bulletin. 2012; 57(26):3409-18. https://doi.org/10.1007/s11434-0125183-2

7. Alyoshin B, Dutov A, Manturov D, Chernyshev S. On the national plan for the development of science and technology in the aircraft industry for the period until 2025 and for the future. The Flight. 2013; 1:5-15.

8. Sid K. Project management demystified. 1st Ed. McGrawHill Education. 2004. p. 1-288.

9. Directive 2005/32/EC of the European parliament and of the council. 2005. https://eur-lex.europa.eu/legal-content/ EN/ALL/?uri=CELEX\%3A32005L0032

10. Castri FD. Ecology in a context of economic globalization. BioScience. 2000; 50(4):321-32.

11. Brutyan M. Process of transformation of the organizational and management mechanism under the influence of environmental parameters. Scientific Review: Theory and Practice. 2015; 3:27-33. 
12. Galperin S, Granich V, Gres A, Dzema Y, Kazarinov G, Klochkov V. Methodological foundations and regulations for the management of research and development in hightech industries (on the example of the National Research Center «Institute named after N.Ye. Zhukovsky»)/ under the general editorship of B. S. Alyoshina and A. V. Dutov. M: FGUP GosNIIAS; 2017. p. 1-159.

13. Gorlopanov V, Dudenkov S. Building of the market economy model in russia and innovation processes management. MAGMU Publication Company. 2008.
14. Quality Management System. Technology Audit and Production Reserves. 2014; 15(1/5):1-8.

15. Smagina MN. Gerasimov B, Parhomenko L. Processes of the Quality Management System. Parkhomenko-Tambov: Publishing house of Tamb State Tech; 2006.

16. Doran G. There's a S.M.A.R.T. way to write management goals and objectives. Management Review. 1981; 70(11):35-8. 